\title{
A New Fuzzy Logic based Modeling and Simulation of a Switched Reluctance Motor
}

\author{
Vikas S. Wadnerkar*, Mithun M. Bhaskar ${ }^{\dagger}$, Tulasi Ram Das** and A.D. RajKumar***
}

\begin{abstract}
The switched reluctance motor (SRM) is an older member of the electric machines family. Its simple structure, ruggedness and inexpensive manufacturing potential make it extremely attractive for industrial applications. However, these merits are overshadowed by its inherent high torque ripple, acoustic noise and difficulty to control. In this paper, a control strategy of the angle position control for the SRM drive based on fuzzy logic is illustrated. The input control parameter, the output control parameter and fuzzy control with FAM table formulation strategy are described and simulated with control patterns, and the decision form of the fuzzy control is illustrated and simulated, and the scope of implementing in a Fuzzy based ASIC chip is enlightened with literature support.
\end{abstract}

Keywords: SRM, Error analysis, Estimation, Torque control, Fuzzy logic, Fuzzy systems modeling, Nonlinear estimation, Switched reluctance motor drives

\section{Introduction}

The switched reluctance motor (SRM) is now being used widely in industry because of its advantages over conventional AC/DC Drives [1]. Its speed can be controlled by various methods such as angle position control [2], phase current chopping control [3], fixed angle pulse width modulation (PWM) control [4] and variable angle PWM control [5]. But the essential condition of rotor position estimation or sensing made it quite complex to control. Also, torque ripple and vibration and acoustic noise remain the main drawbacks of SRM. Various researchers have worked on this and came up with a sophisticated controller using Fuzzy and neural [6]-[9]. The application of sensors for rotor position is not viable all the time, therefore various schemes for sensorless position sensing based on static and real time data is developed [10]-[11]. Methods including ANN [12] and Fuzzy logic [13] are now widely used. The benefits of indirect or sensorless sensing are found to be the elimination of electrical connections of the sensor, reduced size, less maintenance, insusceptible to environmental factors and increased reliability. Also, a wide speed range from zero to maximum can be achieved.

The fuzzy logic era got a boost with Prof. Lofti Zadeh, who first explained the fuzzy concept, since which time much literature has been dedicated to fuzzy sets. "Information and Control" [1965], "Fuzzy sets and systems" [1965], "A fuzzy-set-theoretical interpretation of linguistic hedges"

$\dagger$ Corresponding Author: Department of Electrical Engineering, National Institute of Technology, Warangal, India. (mithun.bm@ieee.org)

* Vedanta Aluminum Limited, Jharsuguda, Orissa, India (vikaswadnerkar@gmail.com)

** Department of Electrical and Electronics Engineering, COE, Jawaharlal Nehru Technological University, Hyderabad, India.

*** CVR College of Engineering, Ibrahimpatnam, Hyderabad, Andhra Pradesh, India. (adrajkumar@yahoo.com)

Received: May 6, 2009; Accepted: February 11, 2010
[1972], and related works by others [14]-[16] have been produced to explain the fuzzy logic concept. A fuzzy logic based turn off angle compensator for torque ripple reduction in SRM is proposed [17]. It has been proven that high level of robustness and reliability can be achieved using fuzzy logic based position estimation for sensorless SRMs [18]. A position sensorless scheme is described using fuzzy modeling, estimation and prediction. Rotor position is estimated from static and real time motor data [19], though noise in torque remains a challenge for researchers. Various torque ripple minimization techniques with linear and nonlinear models have been studied [20]. Using this, various dynamic analysis in the estimation algorithm provided robustness and resistance to the effects of input noise using fuzzy control has been proposed [21]. Fuzzy logic based modeling and an angle estimation [22] scheme for flux characteristics has been studied [23]. In all literature it has been observed that fuzzy and neural network based control for angle or rotor position estimation gives the best accuracy and robust performance.

This paper presents a unique fuzzy logic based simulation for a 6/4 SRM. Various schemes for rotor position sensing using fuzzy logic to enhance the performance of an SRM has been simulated and tested. The simulation method is opted on its merits, and a hardware comparison of the same is published separately.

\section{Construction of SRM}

The physical appearance of a switched reluctance motor highly resembles that of other conventional rotating machines (AC and DC), induction motors, etc. The construction of a $6 / 4$ (6 stator poles, 4 rotor poles) poles SRM has doubly salient construction. Usually, the number of stator and rotor poles is even, and the construction is well explained in [24]-[26]. The windings of the SRM are simpler 
than those of other types of motors, and winding exists only on stator poles, and is simply wound on it with no winding on the rotor poles. The winding of opposite poles is connected in series or in parallel forming a number of phases, and exactly half the number of stator poles, and the excitation of a single phase excites two stator poles. The rotor has a simple laminated salient pole structure without winding. SRMs have the advantage of reducing copper lost while its rotor is winding. Its stampings are made preferably of silicon steel, especially in higher efficiency applications, and for aerospace application the rotor operates at very high speeds, requiring the use of cobalt, iron and other variants. The air gap is kept as minimal as possible $(0.1$ $\mathrm{mm}$ to $0.3 \mathrm{~mm}$ ), and the rotor and stator pole arc should be kept the same. It is advantageous if the rotor pole arc is larger than the stator pole arc. The construction of an $8 / 6$ SRM (stator and rotor) is shown in Fig. 1.
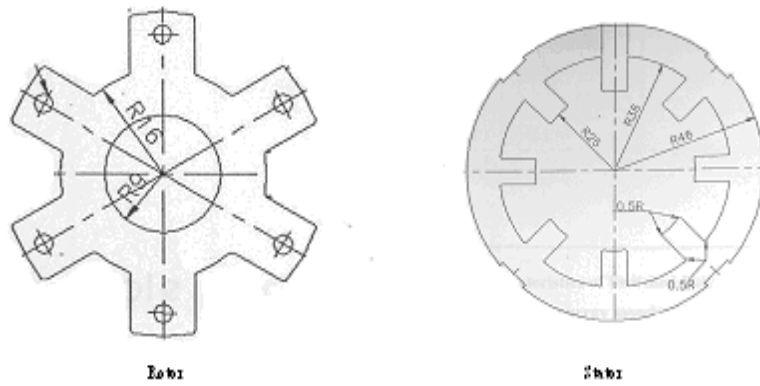

Fig. 1. 8/6 SRM portrayal using AutoCAD.

\section{Torque Production in Switched Reluctance Motor}

In SRMs, torque is developed because of the tendency of the magnetic circuit to adopt the configuration of minimum reluctance i.e. the rotor moves in line with the stator pole thus maximizing the inductance of the excited coil. The magnetic behavior of the SRM is highly nonlinear. But by assuming an idealistic linear magnetic model, the behavior pattern of the SRM can be adjusted with ease without serious loss of integrity from the actual behavior pattern. The most general expression for the torque produced by one phase at any rotor position is

$$
T=[\partial W / \partial \theta]
$$

Since

$$
\mathrm{W}^{`}=\text { Co-energy }=1 / 2 F \Phi=1 / 2 N I \Phi
$$

This equation shows that input electrical power goes partly to increase the stored magnetic energy $(1 / 2 L * i 2)$ and partly to provide mechanical output power given by

$i 2 / 2 x d L / d \theta x \omega$
The latter being associated with the rotational EMF in the stator circuit.

Neglecting saturation non-linearity

$$
\begin{gathered}
\mathrm{L}=\text { Inductance }=N \Phi / I \\
T=1 / 2 i 2 d L / d \theta
\end{gathered}
$$

This equation shows that the developed torque is independent of the direction of current but only depends on the magnitude of the current and the direction of $d L / d \theta$.

\section{Control Strategies}

Different control strategies such as Voltage control [27][28], PI and PID control [29], and hysteresis control [30], can be used for the control of an SRM. However, these control techniques produce more noise and torque ripple reduction is difficult. Therefore, more advanced control techniques need to be used which will minimize the noise and ripples in torque. Hence, a fuzzy logic and neural network [31] based controller is studied and a fuzzy based controller is proposed. The operation of a fuzzy controller is split into three stages: Justification of crisp input values, fuzzy inference using a knowledge base, and defuzzification of the result of the inference process to give crisp output values, which is used for controlling. The complete cycle of the fuzzy controller is illustrated in Fig. 2 and is used to simulate the hysteresis current control where speed is used as the reference. The current reference changes $\operatorname{Ireff}(w, \Phi)$ are used generating a speed error $(e=w r e f-w a c t)$ and its changes $(\mathrm{Ce})$.

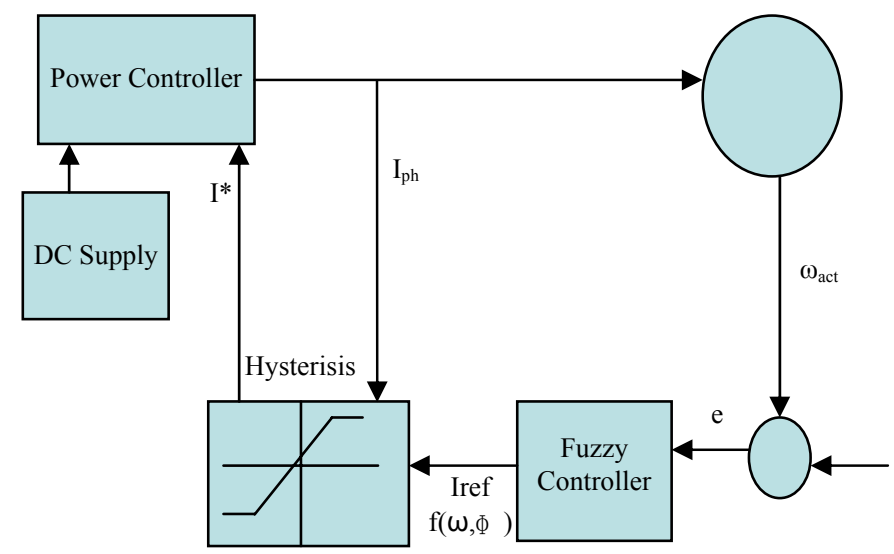

Fig. 2. Block diagram of proposed fuzzy controller.

\section{Modeling of Switched Reluctance Motor}

Mathematical modeling has been exemplified in Equations (1.1) - (1.5), and the modeling of the SWM (8/6) and the expansion of one of the phases is shown in Figs. 3 and Fig. 4 (Matlab v7.5 is exclusively used for all simulations). 


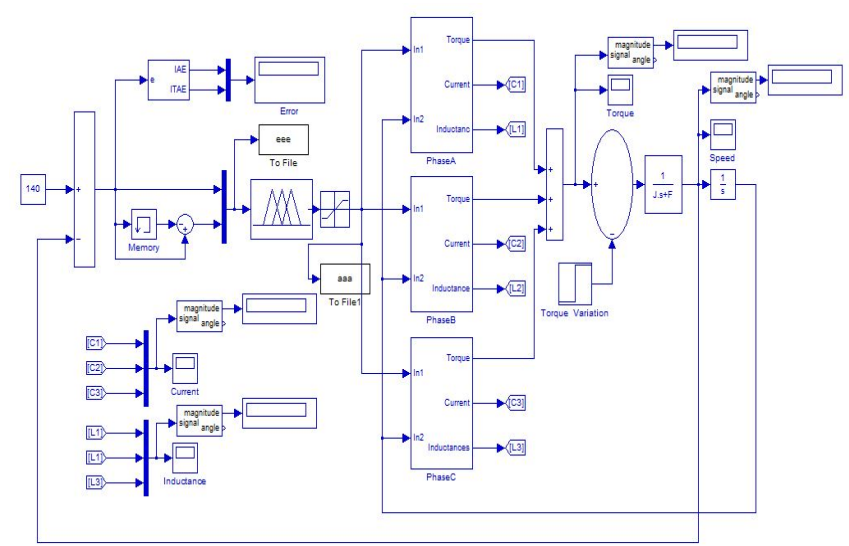

Fig. 3. Linear model of SRM.

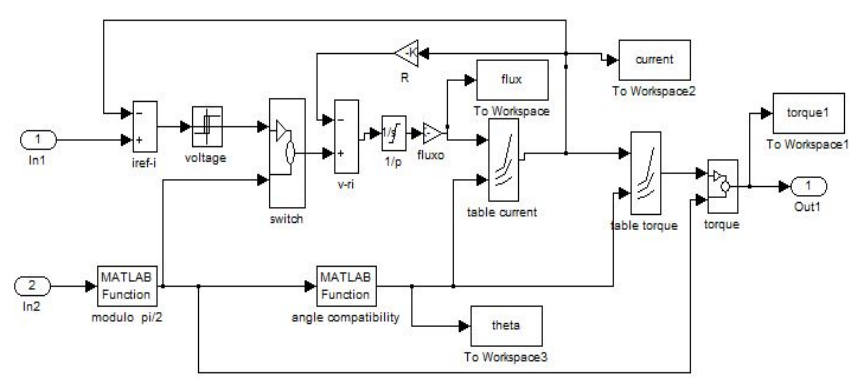

Fig. 4. Expanded phase view of 8/6 SRM.

\section{Modeling of Fuzzy Controller}

Fuzzy sets are developed for the angular position $\Theta$ and the speed error $e(w e)$. The membership function identifies the angular position that will produce positive and negative torque. The membership functions are denser around zero to make the controller more sensitive around the operating point. The fuzzy rule base for input, error and output membership functions are shown below (Figs. 5-7).

Table 1. Developed fuzzy rule base

\begin{tabular}{c|c|c|c|c|c|c|c}
\hline $\mathrm{e} \backslash \mathrm{Ce}$ & $\mathrm{NB}$ & $\mathrm{NM}$ & $\mathrm{NS}$ & $Z$ & PS & PM & PB \\
\hline $\mathrm{NB}$ & NB & NB & NB & NB & NM & NS & Z \\
\hline NM & NB & NM & NS & Z & PS & NB & NB \\
\hline NS & NM & NS & $Z$ & PS & PM & NB & NM \\
\hline Z & NS & $Z$ & PS & PM & PB & NB & NS \\
\hline PS & Z & PS & PM & PB & PB & NS & Z \\
\hline PM & PS & PM & PB & PB & PB & Z & PS \\
\hline PB & PM & PB & PB & PB & PB & NB & NB \\
\hline
\end{tabular}

Where, 'NB' represents Negative Big;

NM: Negative Medium

NS: Negative Small

Z: Zero,

PS: Positive Small

PM: Positive Medium

PB: Positive Big,

E: Error

CE: Change in Error
- Input Membership Functions

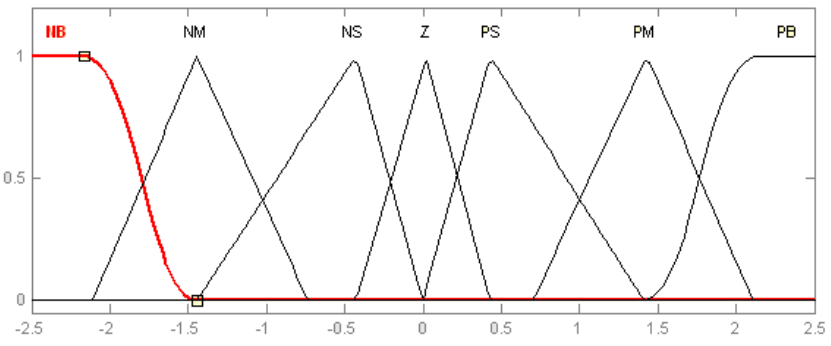

Fig. 5. Fuzzy change in error membership function.

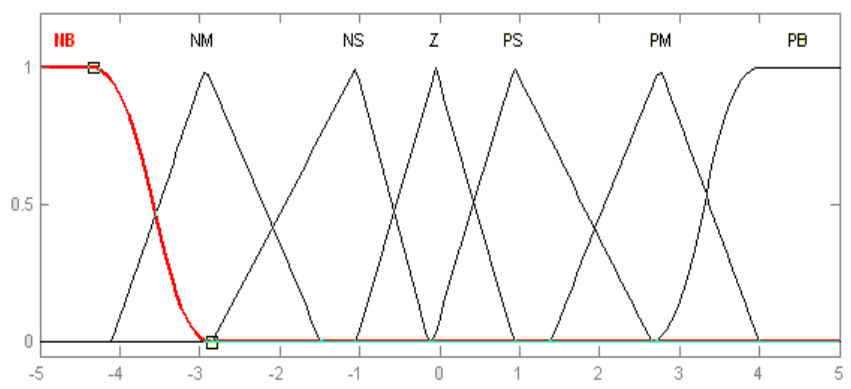

Fig. 6. Fuzzy error membership function.

- Output Membership Functions

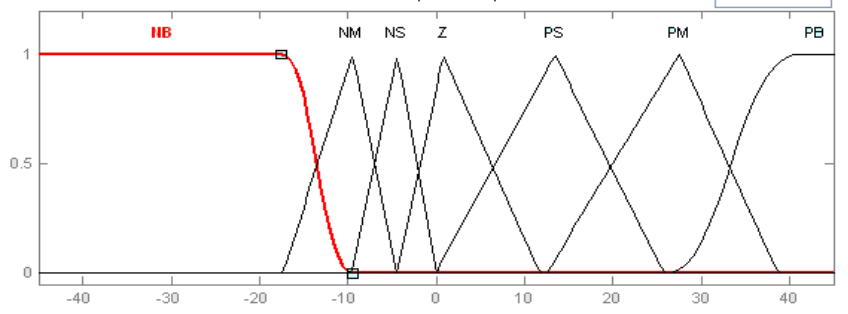

Fig. 7. Fuzzy output membership function.

The rules for generating the command current for one phase is proposed as: If the error is NB and the changeerror is $\mathrm{NB}$, then current is $\mathrm{NB}$; and if the error is $\mathrm{NM}$ and the change-error is NB, then the current is NB; while if the error is NS and the change-error is NB, then the current is NB. And again: If the error is $\mathrm{Z}$ and the change-error is NB, then the current is $\mathrm{NB}$; and if the error is PS and the change-error is $\mathrm{NB}$, then the current is NB; and if the error is $\mathrm{PM}$ and the change-error is $\mathrm{NB}$, then the current is NS; and if the error is $\mathrm{PB}$ and the change-error is $\mathrm{NB}$, then the current is $\mathrm{Z}$. If the speed error is positive and the angular position is such that positive torque is produced, the control rules will command the current that is proportional with the speed error.

\section{Simulation and Experimental System}

Simulation has been done with Mathworks MATLAB version 7.5. Current in different phases of stator winding, torque developed in the motor, inductance of each phase and the speed of the motor with reference to the angle of 
rotation are illustrated below (Figs. 8-10). Hysteresis current control together with fuzzy logic is implemented in the simulation. Various results expressing the performance using fuzzy controller are illustrated in Figs. 10-13. Performance can be observed for the current in one phase, and the inductance profile, speed and torque obtained with respect to time (speed), and it is established that fuzzyhysteresis control has better scope in SRM control design. The ease of implementing fuzzy on chips is available in [32]-[35], and this takes this controller into wider applications.

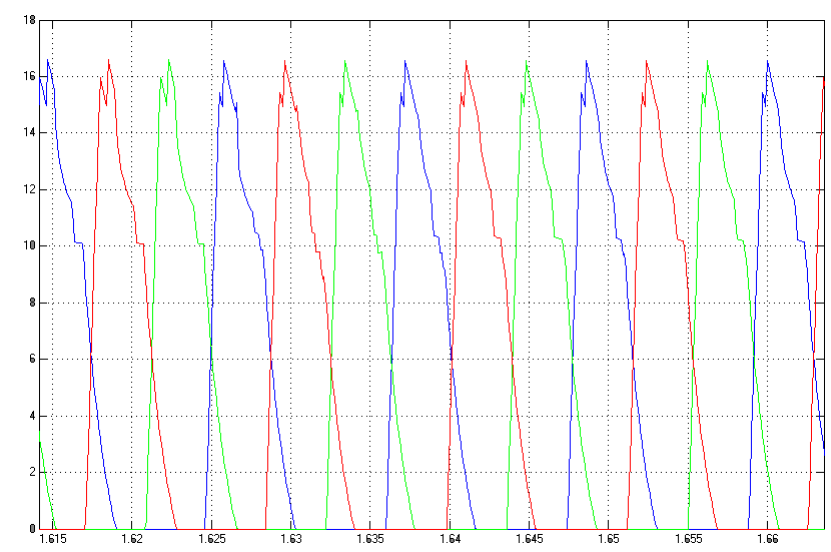

Fig. 8. Current under full load.

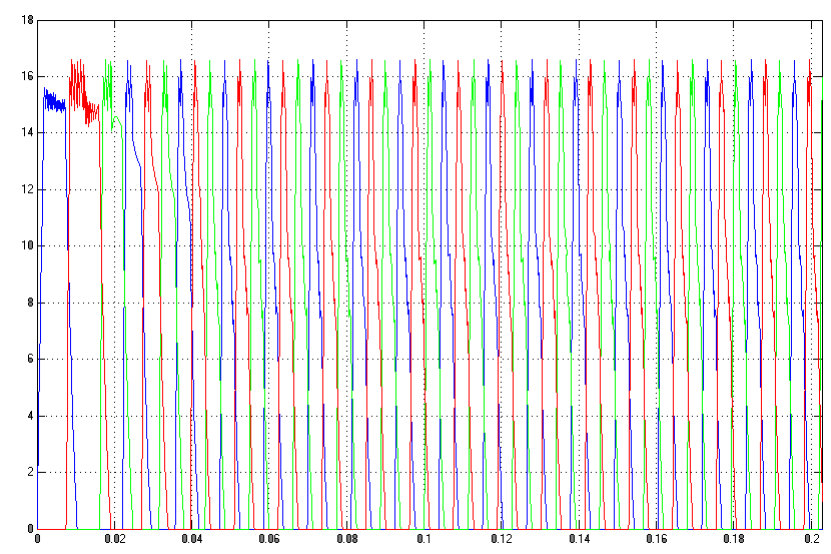

Fig. 9. Current under no-load.

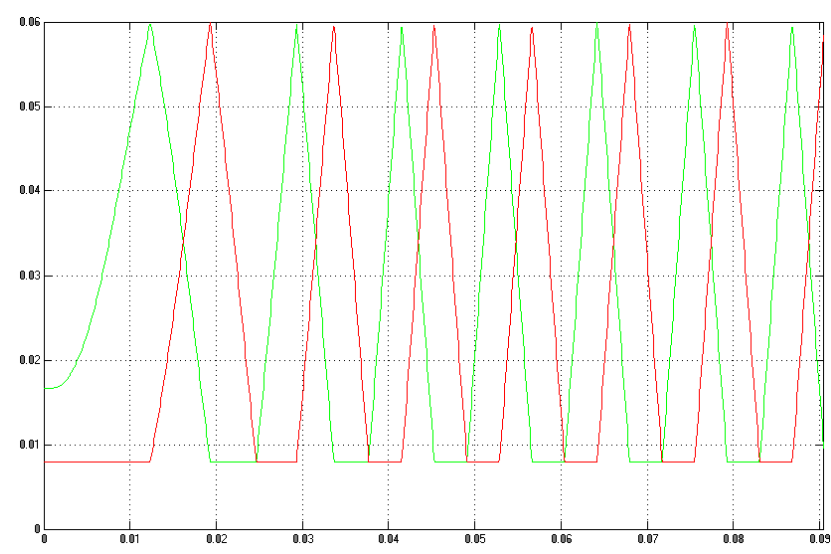

Fig. 10. Inductance profile of SRM.

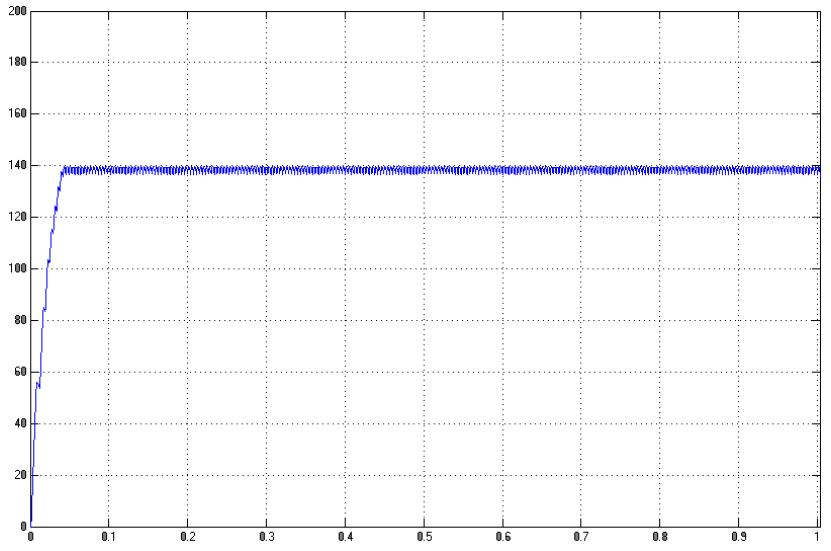

Fig. 11. Speed profile of SRM.

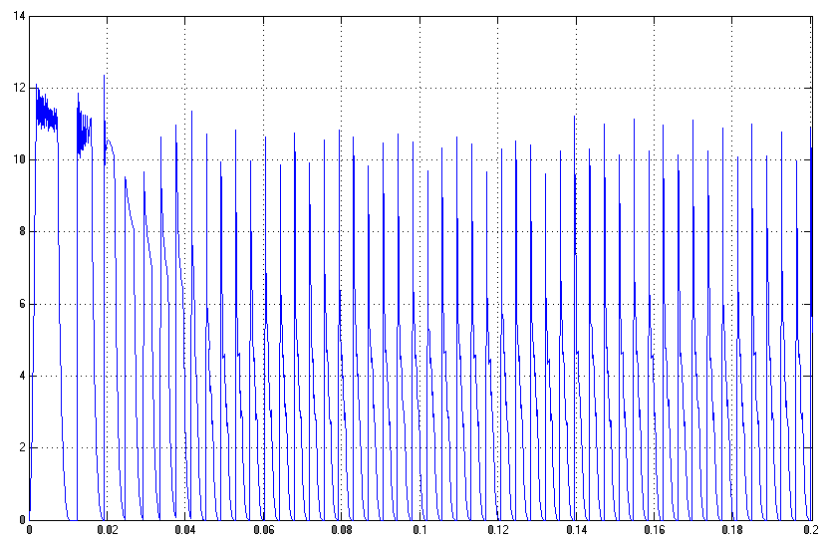

Fig. 12. Torque profile of SRM.

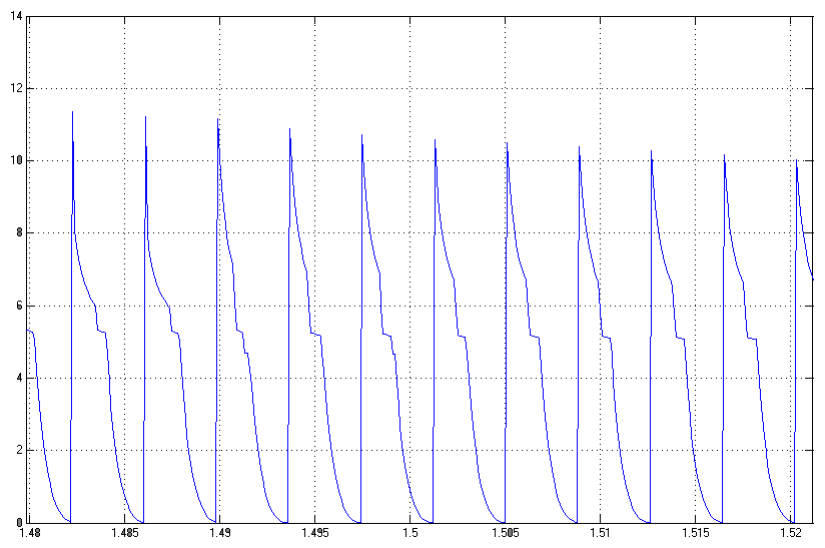

Fig. 13. Torque under loading condition.

\section{Conclusion}

In this paper, an improved fuzzy logic based sensorless rotor position estimation scheme with high accuracy is used to control the speed for an $8 / 6$ switched reluctance motor (SRM). An optimized fuzzy motor model with compact fuzzy rules is implemented here to calculate the rotor position from the current and flux waveforms. A fuzzy logic based optimal phase selector and a predictive filter are 
realized to improve the estimation accuracy. The results obtained are as expected and prove that fuzzy logic is a powerful tool and offers superior improvement in drive performance. Hardware implementation and a neural network based SRM drive controller has already been implemented and published by the same authors. The future scope of implementing the fuzzy controller in ASIC chip and literature has also been included in this paper to assist further research in this area.

\section{Future Scope}

The fizzy control technique used for the control of switched reluctance motors was found to reduce noise compared to other advanced techniques such as neural networks used for minimization of noise and ripple. It is proposed to research a combination of fuzzy and neural techniques to be used simultaneously for better control and noise reduction.

\section{Appendix}

\begin{tabular}{c|c|c}
\hline SN & Item & Quantity \\
\hline 1 & No of Stator / Rotor Pole & $6 / 4$ \\
\hline 2 & Supply Voltage & $150 \pm 50 \mathrm{~V} \mathrm{DC}$ \\
\hline 3 & Stator Current & $5 \mathrm{Amp} / \mathrm{Ph}$ \\
\hline 4 & Per Phase Resistance R & $1.30 \mathrm{ohms} / \mathrm{Ph}$ \\
\hline 5 & Minimum Inductance per phase $\mathrm{L}_{\min }$ & $8 \mathrm{mH}$ \\
\hline 6 & Maximum Inductance $\mathrm{L}_{\max }$ & $60 \mathrm{mH}$ \\
\hline 7 & Moment of Inertia J & $0.0013 \mathrm{~kg} \mathrm{~m}$ \\
\hline
\end{tabular}

\section{References}

[1] K. M. Rahman, B. Fahimi, G. Suresh, A. V.. Rajarathnam and M.. Ehsani, "Advantages of Switched Reluctance Motor Applications to EV and HEV: Design and Control Issues," Proceedings of IEEE Industry Applications Society Annual Meeting, Vol. 1, pp. 327-334, 1998.

[2] Guiying Song, Hexu Sun, Lei Huang and Jiandong Chu, "Microstep position control of switched reluctance motors," International Conference on Power Electronics and Drive Systems, Vol. 2, No. 17-20, pp. 944-947, Nov. 2003.

[3] Michael James Turner and Charles Richard Elliott, "Current chopping in switched reluctance drive systems," US Patent No. 6639378.

[4] Hao Chen, Jianguo Jiang and Chao Zhang, "Simulation of braking control for switched reluctance motor drive," Proceedings of International Conference of Power system Technology, Vol. 1, pp. 201-204, 2000.

[5] H. Chen, X. Wang, X. Zan and X. Meng, "Variable angle control for switched reluctance motor drive based on fuzzy logic," International Conference on Power Electronics and Drive Systems, Vol. 2, No. 1720, pp. 964-968, Nov. 2003.
[6] S. Mir, M. S. Islam, T Sebastian and I. Husain, "Fault-Tolerant Switched Reluctance Motor Drive Using Adaptive Fuzzy Logic Controller," IEEE Transactions on Power Electronics, Vol. 19, No. 2, pp. 289-295, March 2004.

[7] Hao Chen, Dong Zhang, ZiYue Cong and ZhiFeng Zhang, "Fuzzy logic control for switched reluctance motor drive," Proceedings of International Conference on Machine Learning and Cybernetics, Vol. 1, pp. 145-149, 2002.

[8] A. D. Cheok and N. Ertugrul, "Use of Fuzzy Logic For Modeling, Estimation, And Prediction In Switched Reluctance Motor Drives," IEEE transactions on Industrial Electronics, Vol. 46, No. 6, pp. 1207-1224, Dec. 1999.

[9] A. Derdiyok, N. Inanc, V. Ozbulur, H. Pastaci and M. O. Bilgic, "Fuzzy Logic Based Control of Switched Reluctance Motor To Reduce Torque Ripple," Proceedings of IEEE International Electric Machines And Drives Conference, 18-21 pp. 9.1-9.3, May 1997.

[10] A. Cheok and N. A. Ertugrul, "Model Free Fuzzy Logic Based Rotor Position Sensorless Switched Reluctance Motor Drives," Proceedings of 31st IEEE Industry Applications Conference, Vol. 1, pp. 76-83, 1996.

[11] S. Bolognani and M. Zigliotto, "Fuzzy logic control of a switched reluctance motor drive," IEEE Transactions on Industry Applications, Vol. 32, No. 5, pp. 1063-1068, Sept.-Oct. 1996.

[12] V. Rajarathnam, B. Fahimi and M. Ehsani, "Neural Network Based Self Tuning Control of a Switched Reluctance Motor Drive to Maximize Torque per Ampere," IAS Conference Record, 1997.

[13] A. Cheok and N. A Ertugrul, "Model Free Fuzzy Logic Based Rotor Position Sensorless Switched Reluctance Motor Drives," IEEE Industry Applications Conference, Vol. 1, pp. 76-83, 1996.

[14] Zhongfang Wang, A. D. Cheok and Lim Khiang Wee, "Sensorless Rotor Position Estimation Algorithm for Switched Reluctance Motors Using Fuzzy Logic," IEEE Specialists Conference on Power Electronics, Vol. 3, pp. 1701-1706, 2001.

[15] B. Singh, V. K. Sharma and S. S. Murthy, "Performance Analysis of Adaptive Fuzzy Logic Controller for Switched Reluctance Motor Drive System," IEEE Industry Applications Conference, Vol. 1, pp. 571-579, 1998.

[16] N. A. Azli and W.S. Ning, "Application of fuzzy logic in an optimal PWM based control scheme for a multilevel inverter," International Conference on Power Electronics and Drive Systems, Vol. 2, pp. 1280-1285, 2003.

[17] M. Rodrigues, P. J. Costa Branco and W. Suemitsu, "Fuzzy Logic Torque Ripple Reduction by Turn-Off Angle Compensation for Switched Reluctance Motors," IEEE Transactions on Industrial Electronics, Vol. 48, No. 3, June 2001.

[18] N Ertugrul and A. D. Cheok, "Indirect Angle Estimation In Switched Reluctance Motor Drive Using Fuzzy Logic Based Motor Model," IEEE Transac- 
tions on Power Electronics, Vol. 15, No. 6, pp. 10291044, 2000.

[19] M. Costa Branco, P. J. Suemitsu and W. Rodrigues, "Fuzzy Logic Torque Ripple Reduction by Turn-Off Angle Compensation for Switched Reluctance Motors," IEEE Transactions on Industrial Electronics, Vol. 48, No. 3, pp. 711-715, 2001.

[20] A. D. Cheok, and N. Ertugrul, "High Robustness and Reliability of Fuzzy Logic Based Position Estimation for Sensorless Switched Reluctance Motor Drives," IEEE Transactions on Power Electronics, Vol. 15, No. 2, pp. 319-334, March 2000.

[21] A. D. Cheok and N. Ertugrul, "Use of Fuzzy Logic For Modeling, Estimation, And Prediction In Switched Reluctance Motor Drives," IEEE Transactions on Industrial Electronics, Vol. 46, No.6, pp. 1207-1224, 1999.

[22] Nesimi Ertugrul and Adrian Cheok, "Indirect Angle Estimation in Switched Reluctance motor drives using Fuzzy Logic Based Predictor/Corrector," Proceedings of IEEE Power Electronics Specialists Conference, Vol. 1, pp. 845-851, 1998.

[23] A. D. Cheok and N. Ertugrul, "Use of fuzzy logic for modeling, estimation, and prediction in switched reluctance motor drives," IEEE Transactions on Industrial Electronics, Vol. 46, No. 6, pp. 1207-1224.

[24] D. A. Torrey and J.H. Lang, "Modeling a Non-linear Variable Reluctance Motor Drive," IEEE Proceedings, Vo1. 137, pt. B, No. 5, pp. 314-326, Sept. 1990.

[25] T. J. E. Miller, Switched Reluctance Motors and Their Control, Hillsboro, OH, Magna Physics/Oxford Univ. Press, pp. 1-23, 1993.

[26] T. J. E. Miller, J.M. Stephenson, S.R.Macminn and J.R, Hendershot Jr., "Switched Reluctance Drives," IEEE Industry Applications Society, Tutorial Course, 1990.

[27] Jae-Hak Choi, Joonseon S. Ahn and Ju Lee, "The Characteristic Analysis of Switched Reluctance Motor Considering DC-Link Voltage Ripple on Hard and Soft Chopping Modes," IEEE transactions on magnetics, Vol. 41, No.10, pp. 4096-4098, Oct. 2005.

[28] T. J. E. Miller, Electronic Control of Switched Reluctance Machines, pp. 35-97, 2001.

[29] X. M. Zhu, S. K. Panda, P. K. Dash and S. H. Tan, "Experimental investigation of variable structural PID control forswitched reluctance motor drives," Proceedings of International Conference on Power Electronics and Drive Systems, Vol. 1, pp. 205-210, 1997.

[30] A. V. Rajarathnam, K. M. Rahman and M. Ehsani, "Improvement of hysteresis control in switched reluctance motor drives," International Conference on Electric Machines and Drives, pp. 537-539, 1999.

[31] V. Rajarathnam, B. Fahimi and M. Ehsani, "Neural Network Based Self Tuning Control of a Switched Reluctance Motor Drive to Maximize Torque per Ampere," IAS Conference Record, 1997.

[32] Shen Li, "Fuzzy logic control ASIC chip," Journal of Computer Science and Technology, Published by Springer Boston, Vol. 12, No. 3, May 1997.

[33] H. Watanabe, W. D. Dettloff and K. E. Yount, "A VLSI fuzzy logic controller with reconfigurable, cas- cadable architecture," IEEE J. on Solid-State Circuits, Vol. 25, No. 2, pp. 376-382, 1992.

[34] D. Falchieri, A. Gabrielli, E. Gandolfi, M. Masetti, "Design and realization of a two input fuzzy chip running at a rate of $80 \mathrm{ns,"} \mathrm{Proceedings} \mathrm{of} \mathrm{Annual}$ Meeting of the North American Fuzzy Information Processing Society, pp. 329-334, 1997.

[35] H. Watanabe, W. D. Dettloff and K. E. Yount, “A VLSI fuzzy logic controller with reconfigurable, cascadable architecture," IEEE Transactions on SolidState Circuits, Vol. 25, No. 2,pp. 376-382, 1990.

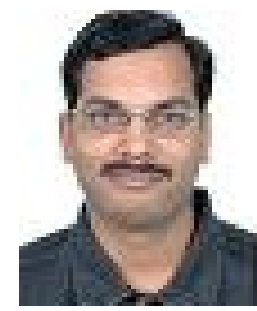

Vikas S Wadnerkar received his B.E. degree from Nagpur University, India in 1997, his M.E. degree from S. G. SITS, Indore, under R. G. P. V. Bhopal, India, and is currently pursuing his $\mathrm{Ph} . \mathrm{D}$. degree in Electrical Engineering at Jawaharlal Nehru Technological University, Hyderabad, India. His areas of Interest include power electronics control of electrical machines, advances in power electronics. Presently he is with Vedanta Aluminum Limited as Manager (Training and Development).

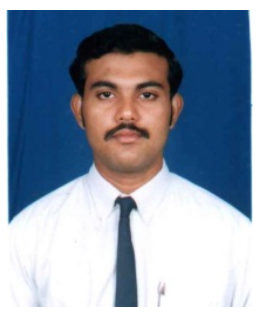

Mithun M. Bhaskar is presently a Student at the National Institute of Technology, Warangal, India. He graduated in Electrical Engineering and Specialized in electrical drives and controls in 2004 and 2007, respectively, from Pondicherry University. He worked at the teaching faculty at SREC, Warangal, India. His present interests include multilevel inverters, artificial intelligence and metalheruistic technique applications, power system security and state estimation. He has a few publications of international and national level to his credit.

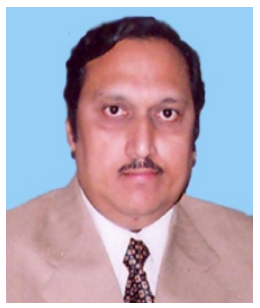

Dr. G Tulasi Ram Das has specialized in power electronics and drives. His research interests include simulation studies on drives for PMSMs. He has 17 years of experience. He delivered invited lectures at institutes such as Anna University, Chennai, IEEE, Hyderabad Chapter, and BHEL R\&D. He is conducting a research project funded by AICTE, and has a few publications of national and international level. He has previously guided three Ph.D. candidates and is presently guiding four Ph.D. candidates

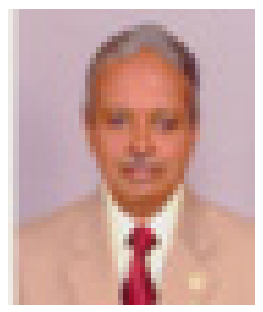

Dr. A. D. Rajkumar is a Principal of CVR College of Engineering, Ibrahimpatnam, Hyderabad, Andhra Pradesh, India. His specialization is in power electronics and microprocessors. He has published a number of research papers in national and international journals and is a member of various technical committees. 